\title{
Inovação e sustentabilidade: a postura inovadora das cooperativas agropecuárias atuantes na Região Sul do Brasil
}

\author{
Innovation and sustainability: the innovative stance of agricultural \\ cooperatives operating in the Southern Brazil
}

\author{
Adilson Carlos Rocha', Pedro Jose Steiner Neto ${ }^{\text {II }}$ \\ 'Universidade Estadual do Oeste Do Paraná. adilson28@hotmail.com \\ "Universidade Positivo. pedrosteinerneto@gmail.com
}

\section{RESUMO}

Ao conceber a sustentabilidade dos negócios como uma contribuição efetiva para o desenvolvimento sustentável, as inovações passam a ter outros critérios de avaliação além daqueles convencionais, onde as inovações devem gerar resultados econômicos, sociais e ambientais positivos, de forma simultânea atendendo a todas as partes interessadas. A partir destas concepções, este estudo teve como objetivo caracterizar as cooperativas agropecuárias atuantes na região sul do Brasil em função de sua postura inovadora tanto em produtos quanto em processos, considerando as dimensões da sustentabilidade. Como procedimentos metodológicos, fez-se uso da abordagem quantitativa de pesquisa, com o desenvolvimento de um survey cross-sectional com uma amostra de 93 cooperativas agropecuárias. A partir do levantamento junto a 38,7\% do universo de cooperativas agropecuárias atuantes na Região Sul do Brasil, definiu-se uma taxonomia composta por quatro clusters, inferindo que há uma diferença no foco para a inovação em produtos e processos. Os resultados demonstraram também que há diferença entre os clusters quando consideradas as dimensões econômica, ambiental e social.

Palavras-chave: desempenho inovador, sustentabilidade, cooperativas agropecuárias. 


\section{ABSTRACT}

By designing business sustainability as an effective contribution to sustainable development, innovations will have other evaluation criteria than conventional ones, where innovations must deliver positive economic, social and environmental outcomes while simultaneously serving all stakeholders. Based on these concepts, this study aimed to characterize agricultural cooperatives operating in the southern region of Brazil due to their innovative stance in both products and processes, considering the dimensions of sustainability. As methodological procedures, the quantitative research approach was used, with the development of a cross-sectional survey with a sample of 93 agricultural cooperatives. Based on the survey of $38.7 \%$ of the group of agricultural cooperatives operating in the Southern Region of Brazil, a taxonomy was defined as four clusters, inferring that there is a difference in the focus for innovation in products and processes. The results also showed that there is a difference between clusters when considering economic, environmental and social dimensions.

Keywords: innovative performance, sustainability, agricultural cooperatives.

\section{INTRODUÇÃO}

A conjuntura atual exige que as organizações considerem os aspectos inerentes à inovação em produtos quanto nas operações de serviços. A inovação parece ser um elemento essencial no âmbito estratégico e no modus operandi das organizações, o que pressupõe que elas desenvolvam continuamente recursos tangíveis e intangíveis para inovar de forma incremental ou radical, buscando ser competitivas e sustentáveis em seu ambiente mercadológico.

Nesse novo contexto, se a sustentabilidade dos negócios for entendida como uma contribuição efetiva para o desenvolvimento sustentável, então as inovações passam a ter outros critérios de avaliação além daqueles convencionais. De acordo com os pressupostos que fundamentam a sustentabilidade, as inovações devem gerar resultados econômicos, sociais e ambientais positivos, de forma simultânea, atendendo a todas as partes interessadas, ou seja, a um grupo de stakeholders, tanto de forma direta quanto indireta.

As relações existentes entre a inovação e a sustentabilidade parecem ser incipientes no ambiente organizacional, no qual as organizações almejam manterem- 
se competitivas, principalmente em aspectos inerentes à gestão dos impactos socioambientais relacionados à atividade produtiva. Nessa conjuntura, as práticas de gestão sustentáveis parecem ser importantes e estão ancoradas no processo de inovação.

Ao se comprometer com o desenvolvimento sustentável, as organizações devem necessariamente mudar sua estratégia de atuação para, no mínimo, reduzir os impactos ambientais e sociais adversos. Essa nova concepção estratégica nas organizações requer uma nova maneira de encarar a inovação, ou seja, buscar um desempenho inovador no âmbito das dimensões econômica, ambiental e social que contribua para o alcance do desenvolvimento sustentável.

Dentre uma diversidade de cadeias ou setores produtivos, este estudo destaca as organizações cooperativas agropecuárias, caracterizadas por uma estrutura organizacional e governança diferenciada das demais organizações, porém, consideradas importantes para a cadeia de valor do agronegócio nacional, onde funcionam como sociedades de pessoas e desempenham um papel no desenvolvimento local e regional. Segundo a Organização das Cooperativas do Brasil OCB (2015), estas organizações respondem por 5,4 \% do PIB brasileiro.

Destaca-se ainda o principal desafio das sociedades cooperativas agropecuárias em manterem-se como organizações competitivas, capazes de desenvolver estratégias inovadoras para enfrentar mercados competitivos e, ao mesmo tempo, atenderem às necessidades dos seus stakeholders, principalmente seus cooperados, e ainda mitigarem os impactos causados pela atividade como o desmatamento e consequente redução da biodiversidade, pela utilização de produtos químicos e agrotóxicos que contaminam o solo e lençóis freáticos, entre outros danos no âmbito das dimensões ambiental e social. 
A partir destas considerações, o problema de pesquisa proposto constitui-se em: Qual é a postura inovadora das organizações cooperativas agropecuárias considerando as dimensões econômica, ambiental e social? Diante desta questão, este estudo teve como objetivo caracterizar as cooperativas agropecuárias atuantes na região sul do Brasil em função do foco para a inovação tanto em produtos quanto em processos, considerando as dimensões da sustentabilidade.

\section{INOVAÇÃO E DESEMPENHO INOVADOR}

O processo inovador é um dos instrumentos fundamentais considerados pelas organizações, principalmente pelo crescimento e entrada em novos mercados, buscando ampliar o market share e proporcionar à organização uma vantagem competitiva sustentável. Motivados pelo aumento da concorrência nos mercados globais, às organizações passaram a entender a importância da inovação, uma vez que mudanças tecnológicas e de competição global intensa rapidamente corroem o valor acrescentado aos produtos e serviços existentes (GUNDAY et al., 2011).

De acordo com o Manual de Oslo (OCDE, 2007), estudos sobre inovação e discussões de políticas de gestão enfatizam a importância de se considerar a inovação numa perspectiva ampla. Uma visão fundamentada em conhecimento concentra-se nos processos interativos por meio dos quais o conhecimento é criado e trocado internamente e entre outras organizações. Para Lundvall (2010), a inovação é considerada como o resultado de um processo de aprendizagem interativa, envolvendo a interação entre utilizadores e produtores e suas interações entre organizações e outras instituições fornecedoras, produtoras e formadoras de conhecimento (universidades e instituições de ensino superior, laboratórios e centros de pesquisa e desenvolvimento, e institutos de pesquisa governamentais), e ainda, a interação entre outras partes interessadas. 
Segundo o Manual de Oslo (OCDE, 2007), quatro tipos diferentes de inovação podem ser desenvolvidos, ou seja: (i) inovação de produto; (ii) de processo; (iii) de marketing; e (iv) organizacional. As inovações de produtos e processos estão intimamente relacionadas com o conceito de evolução tecnológica dentro de um sistema tecnológico, que, segundo Freeman (1984), consiste em sistemas formados por constelações de inovações, técnica e economicamente inter-relacionados que afetam vários fatores da produção.

A inovação em produto pode ser a introdução de algo novo ou melhorado em relação a suas características ou usos previstos, incluindo melhorias significativas em especificações técnicas, componentes e materiais, softwares incorporados, facilidade de uso ou outras características funcionais. Inovações de produto podem utilizar novos conhecimentos ou tecnologias, ou podem ser baseadas em novos usos ou combinações de conhecimento existente ou tecnologias. O termo produto abrange os bens e serviços (OCDE, 2007).

De acordo com o Manual de Oslo (OCDE, 2007), a inovação em processo entende-se como a implementação de uma nova produção ou significativamente melhorar o método de entrega. Isto inclui alterações significativas nas técnicas, equipamento e/ou softwares. As inovações de processo podem ter a intenção de diminuir os custos unitários de produção ou entrega para melhorar a qualidade, ou para produzir ou entregar produtos novos ou significativamente melhorados.

A inovação é definida por Tidd e Bessant (2015) como um processo de tradução de ideias em processos, produtos ou em serviços que sejam úteis. O processo de inovação pode acontecer de duas formas: incremental ou radical. A inovação incremental gera pequenas melhorias em produtos, processos ou serviços existentes, aprimorando a forma de fazer algo que já era feito anteriormente. Já a inovação radical engendra rupturas mais intensas, causando uma mudança profunda nos serviços, nos produtos ou nos processos. 
Para Gunday, et al. (2011), a inovação é considerada como uma evolução e novas aplicações, com o objetivo de lançar a novidade para o mercado, podendo ser concebida como a transformação do conhecimento em valor mercadológico ou organizacional. A inovação tem grande importância devido ao seu potencial para aumentar a eficiência e a rentabilidade dos processos. Portanto, a inovação desempenha um papel significativo na criação de diferenças de desempenho e competitividade entre as organizações, regiões e até países.

\subsection{Indicadores de desempenho inovador}

Grande parcela dos pesquisadores sobre inovação reconhece que o processo ou atividade inovadora são complexos e, consequentemente, difíceis de serem mensurados e avaliados, portanto, é evidente o desafio para pesquisadores que investem esforços em entender os seus determinantes (MAKKONEN; VAN DER HAVE, 2012). Segundo Madureira et al. (2013), as preocupações com a identificação, a medição e a valorização da inovação são visíveis a partir das décadas de 1970 e 1980 e estão, durante este período, estreitamente correlacionadas com o impacto da inovação no crescimento econômico.

Diante da complexidade em avaliar e mensurar a inovação, Makkonen e Van Der Have (2012) sugerem outra forma de medição para inovação com a aplicação de índices de inovação compostos, os quais foram introduzidos pela primeira vez na década de 1990 para avaliar o nível de inovação nas organizações. Estes pesquisadores sugerem os indicadores mais utilizados para construir índices que mensuram a inovação, sendo estes: (i) pesquisa e desenvolvimento; (ii) patentes; (iii) inovação em produtos e processos; (iv) desenhos e marcas; e (v) certificações e publicações científicas. Porto (2013) sugere os indicadores: (i) dispêndios e pessoal aplicados em P\&D; (ii) balanço de pagamentos de ativos intangíveis; (iii) inovações em 
produtos e processos; (iv) patentes; e (v) recursos humanos engajados em atividades científicas e tecnológicas.

Para além de indicadores de P\&D ou de patentes depositadas, Reichert, Camboim e Zawislak (2015) destacam que se devem considerar outros esforços de mudança e novidade, como adaptações em produtos, novos arranjos operacionais, adequações em práticas de gestão ou novas técnicas de marketing. Trata-se de atividades que não seriam capturadas pelos modelos tradicionais de inovação, mas que podem indicar desempenho significativo para as organizações.

Para Gunday et al. (2011), o desempenho inovador é a combinação de resultados globais da organização, como resultado de renovação e melhoria de esforços feitos considerando uma diversidade de aspectos inovadores e, entre eles, estão processos, produtos e estrutura organizacional. Dessa forma, destacam que o desempenho inovador é uma construção composta com base em vários indicadores de desempenho relativos, por exemplo, novas patentes, anúncios de novos produtos, projetos, processos e novos arranjos organizacionais.

\subsection{Indicadores de inovação no agronegócio}

Spielman e Kelemework (2009), em seu estudo, destacaram a existência de poucas ferramentas para avaliar a inovação no setor do agronegócio ou da agricultura. Assim, poucos países em desenvolvimento sabem como são dinâmicos, responsivos ou competitivos seus setores agrícolas. O referido estudo sugeriu a necessidade de medidas de inovação no agronegócio, preferencialmente que se estendam além da abordagem das medidas de insumos e produtos, focalizando os processos subjacentes em que as capacidades evoluem e se desenvolvem para criar um setor agropecuário inovador. 
Os estudos sobre a inovação tecnológica no agronegócio, especialmente os realizados no Brasil, desde a década de 1960, mostraram as profundas mudanças ocorridas no setor, da estagnação aos elevados ganhos de produtividade (VIEIRA FILHO; VIEIRA, 2014). A inovação tecnológica no agronegócio, segundo Santos et al. (2012), considera um grande número de fatores e atores presentes no âmbito da cadeia produtiva. Consolida-se na medida em que os métodos de pesquisa levam em consideração as necessidades dos consumidores finais e associam a elas questões como preservação ambiental, uso racional dos recursos, relação custo benefício das tecnologias, aplicabilidade e potencial de adoção.

Em consequência das mudanças nas configurações da economia global e nacional, o Ministério da Agricultura, Pecuária e Abastecimento (MAPA) propôs uma revisão no conceito para a "agroinovação" e a definiu como "[...] uma novidade ou aperfeiçoamento agrícola de produção e distribuição de suprimentos, de operações de produção, de armazenamento, processamento e distribuição de produtos e itens produzidos a partir deles, introduzidos no mercado" (MAPA, 2009, p. 68).

O desenvolvimento de indicadores de inovação no âmbito do agronegócio ainda é tênue na literatura. O estudo desenvolvido por Schvarz Sobrinho (2009), por meio de uma pesquisa exploratória, elegeu um grupo de indicadores com o objetivo de analisar a natureza das inovações em organizações cooperativas agropecuárias. Os indicadores de desempenho que caracterizam as inovações em produtos e processos propostos por Schvarz Sobrinho (2009) basearam-se nas proposições do Manual de Oslo (OECD, 2007). Os indicadores foram classificados com intenção de avaliar a inovação em produtos e em processos. O Quadro 01 apresenta os indicadores utilizados por Schvarz Sobrinho (2009) ao analisar a inovação em produtos no âmbito das cooperativas agropecuárias. 
Quadro 01 - Indicadores de inovação em produtos

\begin{tabular}{|c|}
\hline Indicadores de Inovação em Produtos \\
\hline $\begin{array}{l}\text { 1. Aplicação de recursos financeiros e humanos no período para aumento de conhecimento } \\
\text { tecnológico em produtos }\end{array}$ \\
\hline $\begin{array}{l}\text { 2. Os produtos "commoditizados" são os principais responsáveis pelo faturamento da } \\
\text { cooperativa. }\end{array}$ \\
\hline $\begin{array}{l}\text { 3. Produtos com valor agregado (não commoditizados) são os principais responsáveis pelo } \\
\text { faturamento da cooperativa. }\end{array}$ \\
\hline 4. No período analisado, houve lançamento de produtos inovadores para a cooperativa. \\
\hline $\begin{array}{l}\text { 5. No período analisado, houve lançamento de produtos inovadores em relação ao mercado } \\
\text { concorrente. }\end{array}$ \\
\hline $\begin{array}{l}\text { 6. As inovações de produtos adotadas em determinado período contribuíram para aumento da } \\
\text { produtividade (fazer a mesma coisa em menor tempo, com melhor qualidade e com menor } \\
\text { esforço). }\end{array}$ \\
\hline $\begin{array}{l}\text { 7. Houve aumento no faturamento devido ao lançamento de produtos inovadores (para a } \\
\text { empresa e para o mercado) no período. }\end{array}$ \\
\hline $\begin{array}{l}\text { 8. A cultura organizacional da Cooperativa incentiva a adoção de ideias inovadoras para } \\
\text { produtos. }\end{array}$ \\
\hline 9. Constantemente são introduzidas mudanças significativas nas linhas de produtos existentes. \\
\hline 10. A tecnologia de produtos, atualmente adotada, é inovadora para a cooperativa. \\
\hline $\begin{array}{l}\text { 11. A tecnologia de produtos, atualmente adotada, é inovadora em relação às organizações } \\
\text { concorrentes. }\end{array}$ \\
\hline
\end{tabular}

Fonte: Adaptado de Schvarz Sobrinho (2009).

Para os indicadores de inovação em processos em organizações cooperativas agropecuárias, Schvarz Sobrinho (2009) destaca o conceito do Manual de Oslo (OECD, 2007), já anteriormente apresentado. O Quadro 02 apresenta os indicadores de inovação em processos utilizados por Schvarz Sobrinho (2009). 
Quadro 02 - Indicadores de inovação em processos

\section{Indicadores de inovação em Processos}

1. Em determinado período foram aplicados recursos financeiros e humanos para aumento de conhecimento tecnológico em processos.

2. As inovações de processos adotadas contribuíram para aumento da produtividade (fazer a mesma coisa em menor tempo, com melhor qualidade e com menor esforço).

3. As inovações de processos adotadas na propiciaram evolução suficiente para suportar as mudanças exigidas no ambiente atual.

4. A cultura organizacional da Cooperativa incentiva a adoção de ideias inovadoras em processos.

5. A tecnologia de processo, atualmente adotada pela cooperativa, é mais inovadora do que na década anterior.

6. A tecnologia de processo, atualmente adotada, é mais inovadora do que em relação à concorrência.

Fonte: Adaptado de Schvarz Sobrinho (2009).

Outro estudo recente desenvolvido por Madureira et al. (2013) teve como objetivo identificar os indicadores que seriam mais adequados para medir as boas práticas de inovação no âmbito do agronegócio em Portugal, no período de 2009 a 2012. O citado estudo desenvolveu um conjunto de variáveis e indicadores-chave, os quais foram usados para caracterizar o desenvolvimento e a concretização de boas práticas de inovação nas zonas rurais de Portugal, resultando em três grupos de indicadores: input, processos e resultados. O Quadro 03 apresenta o conjunto de variáveis e indicadores que serviram de base para analisar as inovações no ambiente rural português propostas por Madureira et al. (2013). 
Quadro 03 - Indicadores de inovação

\begin{tabular}{|c|c|c|}
\hline Indicadores (Input) & Indicadores (processos) & Indicadores (Resultados) \\
\hline $\begin{array}{l}\text { Conhecimento e } \\
\text { competências: (existência de) } \\
\text { recursos humanos (RH) em } \\
\text { ciência e tecnologia; RH afetos } \\
\text { a atividades de P\&D. }\end{array}$ & $\begin{array}{l}\text { Número de inovações por tipo - de } \\
\text { produto, de processo, organizacionais } \\
\text { e de marketing -, experimentadas ou } \\
\text { adotadas nos últimos cinco anos. }\end{array}$ & $\begin{array}{l}\text { Número de inovações } \\
\text { criadas e/ou introduzidas } \\
\text { na organização }\end{array}$ \\
\hline $\begin{array}{l}\text { P\&D: despesas em P\&D; } \\
\text { percentagem das vendas } \\
\text { aplicada em P\&D. }\end{array}$ & $\begin{array}{l}\text { Crescimento da produtividade total } \\
\text { (TFP) ou número de alterações } \\
\text { introduzidas nas empresas }\end{array}$ & $\begin{array}{l}\text { Percentagem nas vendas } \\
\text { dos produtos/serviços } \\
\text { inovadores. }\end{array}$ \\
\hline $\begin{array}{l}\text { Financiamento: meios } \\
\text { financeiros próprios; } \\
\text { mobilização de financiamento } \\
\text { privado público. }\end{array}$ & $\begin{array}{l}\text { Formas mistas de inovação: } \\
\text { estratégias complementares de } \\
\text { inovação na indústria e nos serviços }\end{array}$ & $\begin{array}{l}\text { Crescimento do volume de } \\
\text { vendas da organização. }\end{array}$ \\
\hline $\begin{array}{l}\text { Mecanismos de suporte ao } \\
\text { investimento privado em P\&D: } \\
\text { apoios à competitividade; } \\
\text { disposições fiscais; garantias } \\
\text { de crédito; garantias públicas } \\
\text { de financiamento de P\&D. }\end{array}$ & $\begin{array}{l}\text { Inovações - de produto, de processo, } \\
\text { organizacionais e de marketing --, } \\
\text { principalmente incrementais ou } \\
\text { radicais, introduzidas nos últimos } \\
\text { cinco anos. }\end{array}$ & $\begin{array}{l}\text { Divulgação da inovação: } \\
\text { número de artigos em } \\
\text { publicações académicas; } \\
\text { número de referências; } \\
\text { número de ações para } \\
\text { divulgação de } \\
\text { conhecimento, etc. }\end{array}$ \\
\hline $\begin{array}{l}\text { Redes de conhecimento: } \\
\text { aquisição de conhecimentos } \\
\text { através de parcerias externas } \\
\text { (alianças, joint ventures, } \\
\text { consórcios, etc.); aquisição } \\
\text { /venda de conhecimento; } \\
\text { contatos com universidades. }\end{array}$ & $\begin{array}{l}\text { Cadeias de valor: analisa o contributo } \\
\text { da organização para a cadeia de valor } \\
\text { e a criação interna de valor } \\
\text { acrescentado, tendo por base a } \\
\text { informação recolhida para os três } \\
\text { principais produtos da organização } \\
\text { (definidos de acordo com o peso no } \\
\text { respetivo volume de vendas ou } \\
\text { serviços). }\end{array}$ & $\begin{array}{l}\text { Número de patentes e } \\
\text { marcas registadas. }\end{array}$ \\
\hline Barreiras ao & Melhorias de design, na organização e & \\
\hline
\end{tabular}


A mensuração da inovação contemplando as três principais dimensões - input, processo e resultado - propostas, potencializa o entendimento e a compreensão sobre as motivações, os padrões e as dinâmicas de inovação, assim como sobre as suas interações, as quais explicam, em robusta medida, a escolha dos inputs e os resultados observados (MADUREIRA, et al., 2013).

O conjunto de indicadores elencados pelos estudos de Gunday et al. (2011), Makkonen e Van der Have (2012), Tidd e Bessant (2015), Schvarz Sobrinho (2009) e Madureira et al. (2013) compuseram o conjunto de variáveis para analisar o desempenho inovador em produtos e processos nas cooperativas agropecuárias, objeto deste estudo.

\subsection{A sustentabilidade e suas dimensões}

O debate envolvendo o desenvolvimento sustentável é fomentado em diversas áreas do conhecimento. O que potencializa este debate são os inúmeros problemas ambientais, econômicos e sociais evidentes nas últimas décadas, suscitando preocupações com as condições de sobrevivência das próximas gerações (NASCIMENTO, 2012, ELKINGTON, 2011; SACHS, 2008; VEIGA, 2006). De acordo com a CMMAD (1991), o desenvolvimento sustentável é aquele capaz de suprir as necessidades da geração atual, sem comprometer a capacidade de atender as necessidades das futuras gerações.

Diante desta problemática, surgiram diversos movimentos fortalecendo o desenvolvimento sustentável. Este, então, passa a ser uma das principais 
preocupações no ambiente corporativo dos negócios, principalmente nas cadeias produtivas que causam maior impacto na oferta de condições básicas para a sobrevivência do planeta (ELKINGTON, 2011; WU; PAGELL, 2011; DIEGUES, 2008; VIEIRA, 2006).

A sustentabilidade, definida pelo conceito Triple Bottom Line - termo que considera não somente questões econômicas, mas também sociais e de meio ambiente na gestão organizacional - sugere a garantia de oportunidades corporativas e cria um sistema mais transparente, aberto e informativo para os consumidores e outras partes interessadas (ELKINGTON, 2011).

Os problemas ambientais e sociais passaram a impor pressões às organizações, no entanto, estes problemas não são de responsabilidade exclusiva de uma única organização, e sim, de toda uma cadeia produtiva. Desta forma, as organizações e sua cadeia precisam estar preocupadas em desenvolver estratégias para uma cadeia sustentável com o objetivo de satisfazer as necessidades de seus stakeholders (DALÉ; ROLDAN; HANSEN, 2011).

A interação entre organizações, sociedade e meio ambiente provocou alterações nos pressupostos de gestão e desempenho organizacional. De forma que a geração de inovações e a evolução tecnológica passaram a ser condicionadas por outros fatores, além daqueles que influenciam a obtenção da lucratividade decorrente dos processos economicamente eficientes, então novas perspectivas gerenciais surgiram como alternativas viáveis aos processos produtivos (DAROIT; NASCIMENTO, 2004).

De acordo com Schaltegger, Ludeke-Freund e Hansen (2011), estratégias organizacionais preocupadas com a sustentabilidade são de importância crucial para o desenvolvimento sustentável, também para uma organização dirigir com sucesso 
considerando requisitos sociais, legais, políticos e econômicos relacionados com a sustentabilidade em condições de concorrência no mercado.

Para Souza, Silva Filho e Abreu (2014), o papel das organizações na promoção da sustentabilidade é dependente da concepção e implantação de estratégias corporativas que contemplem de forma equilibrada as áreas econômica, ambiental e social. Assim, as organizações estariam contribuindo para o bem-estar das futuras gerações e, ao mesmo tempo, trabalhando para se tornarem sustentáveis e competitivas no seu ambiente de negócios.

A seguir, serão expostos os principais aspectos inerentes a cada dimensão bem como as características que possam evidenciar estes aspectos, nas respectivas dimensões da sustentabilidade. Os aspectos e indicadores inerentes a cada dimensão são oriundos do estudo de Callado (2010), o qual desenvolveu uma ampla pesquisa na literatura, analisando uma diversidade de modelos com objetivo de propor um framework para analisar a sustentabilidade no âmbito do agronegócio brasileiro. Em seu estudo, Callado (2010) revisou propostas que buscavam avaliar a sustentabilidade organizacional por meio de indicadores econômicos, ambientais e sociais.

No âmbito da dimensão econômica, Elkington (2011, p. 111) ressalta que, em sua utilização tradicional, ela é "representada pelos ganhos por ação como parte da contabilidade padrão". Nessa visão tradicional, são poucas as evidências de sobreposições do desempenho econômico frente ao ambiental e social, necessárias na gestão das organizações que têm como objetivo incorporar a sustentabilidade em suas operações.

Segundo Jacobs e Chase (2012), as estratégias organizacionais devem promover o crescimento e aumentar o valor no longo prazo para parte dos interessados na forma de lucratividade. Considerando os aspectos da sustentabilidade, essa 
dimensão vai além dos aspectos que envolvem o lucro, acrescentando benefícios econômicos para a sociedade.

Nascimento (2012) considera que a sustentabilidade econômica está alicerçada no aumento da eficiência da produção e do consumo com economia crescente de recursos naturais, com destaque para recursos de fontes fósseis de energia e os recursos delicados e mal distribuídos, como a água e os minerais. A sustentabilidade na dimensão econômica pode ser avaliada, segundo Callado (2010), por uma gama de aspectos. O Quadro 04 apresenta os indicadores e os respectivos parâmetros a serem considerados na avaliação.

Quadro 04 - Indicadores de sustentabilidade econômica

\begin{tabular}{|c|c|}
\hline Indicador & Parâmetro de avaliação \\
\hline Investimentos éticos & $\begin{array}{l}\text { Analisar a natureza de critérios adotados para a análise de } \\
\text { investimentos. }\end{array}$ \\
\hline $\begin{array}{l}\text { Gastos em saúde e em } \\
\text { segurança }\end{array}$ & $\begin{array}{l}\text { Analisar os gastos da organização com aspectos associados à saúde de } \\
\text { seus funcionários. }\end{array}$ \\
\hline $\begin{array}{l}\text { Investimento em } \\
\text { tecnologias limpas }\end{array}$ & $\begin{array}{l}\text { Analisar os investimentos em tecnologias limpas (energia solar, redes } \\
\text { elétricas controladas por computadores, carros elétricos, } \\
\text { biocombustíveis e materiais limpos). }\end{array}$ \\
\hline Nível de endividamento & $\begin{array}{l}\text { Analisar o endividamento da organização a partir da relação entre o } \\
\text { passivo exigível e o ativo total. }\end{array}$ \\
\hline Lucratividade & $\begin{array}{l}\text { Analisar a lucratividade da organização a partir da relação entre o lucro } \\
\text { líquido e o faturamento total. }\end{array}$ \\
\hline Participação de mercado & Analisar a participação de mercado que a organização possui. \\
\hline Passivo ambiental & $\begin{array}{l}\text { Analisar as agressões ocorridas contra o meio ambiente (água, solo e } \\
\text { ar) e seus eventuais gastos necessários para reabilitá-lo, bem como } \\
\text { multas e indenizações em potencial. }\end{array}$ \\
\hline $\begin{array}{l}\text { Gastos em proteção } \\
\text { ambiental }\end{array}$ & $\begin{array}{l}\text { Analisar os investimentos realizados pela organização que estão } \\
\text { associados à prevenção de acidentes e proteção ambiental. }\end{array}$ \\
\hline
\end{tabular}




\begin{tabular}{|l|l|}
\hline Auditoria & $\begin{array}{l}\text { Analisar a realização de serviços de auditoria realizados no âmbito da } \\
\text { organização. }\end{array}$ \\
\hline $\begin{array}{l}\text { Avaliação de resultados da } \\
\text { organização }\end{array}$ & $\begin{array}{l}\text { Analisar os procedimentos adotados pela organização acerca da } \\
\text { avaliação de resultados e mensuração do seu desempenho. }\end{array}$ \\
\hline Volume de vendas & Analisar o comportamento do volume de vendas apresentado. \\
\hline Gastos com benefícios & Analisar os gastos com pensões e demais benefícios. \\
\hline Retorno sobre capital & $\begin{array}{l}\text { Analisar o retorno sobre o capital investido a partir da relação entre o } \\
\text { lucro líquido e o ativo total. }\end{array}$ \\
\hline Certificações e selos de & Analisar a posse de selos de qualidade para produtos, serviços e \\
qualidade & processos.
\end{tabular}

Fonte: Callado (2010).

Os conceitos atribuídos aos aspectos inerentes ao meio ambiente parecem ser complexos, pois incluem o ecossistema e as funções como a contribuição dos recursos hídricos, gases, flora e fauna. Esse capital natural pode ser visto por meio de dois prismas, o capital natural crítico, inerente à manutenção da vida e dos ecossistemas, e o renovável ou substituível, que pode ser renovado, recuperado ou substituído (ELKINGTON, 2011).

Para Nascimento (2012), a sustentabilidade na dimensão ambiental pressupõe que o modelo de produção e consumo seja compatível com a base de recursos em que se assenta a economia, como um subsistema do meio natural, ou seja, produzir e consumir de forma a garantir que os ecossistemas possam manter sua autorreparação ou capacidade de resiliência.

Nesta dimensão, busca-se atenuar o impacto que as organizações causam ao meio ambiente. Para Jacobs e Chasse (2012), os dirigentes devem se mobilizar para reduzir a "pegada ecológica", gerenciando de forma cuidadosa o consumo de recursos naturais, reduzindo a quantidade de resíduos nocivos ao ambiente. 
Para a dimensão ambiental, Callado (2010) propôs, em seu estudo, um grupo de 16 indicadores. O Quadro 05 apresenta os indicadores e os respectivos parâmetros a serem considerados tanto para tomar decisões estratégicas quanto na avaliação desta dimensão.

Quadro 05 - Indicadores de sustentabilidade ambiental

\begin{tabular}{|c|c|}
\hline Indicador & Parâmetro de avaliação \\
\hline $\begin{array}{l}\text { Sistemas de Gestão Ambiental } \\
\text { (SGA) }\end{array}$ & Analisar a complexidade de práticas de gestão ambiental. \\
\hline Quantidade de água utilizada & Analisar a utilização de água em suas atividades. \\
\hline $\begin{array}{l}\text { Processos decorrentes de } \\
\text { infrações ambientais }\end{array}$ & $\begin{array}{l}\text { Analisar a presença de processos instaurados por não } \\
\text { conformidades ambientais. }\end{array}$ \\
\hline $\begin{array}{l}\text { Treinamento, educação e } \\
\text { capacitação em aspectos } \\
\text { ambientais }\end{array}$ & $\begin{array}{l}\text { Analisar as políticas de treinamento, capacitação e educação } \\
\text { de funcionários. }\end{array}$ \\
\hline Economia de energia & $\begin{array}{l}\text { Houve aumento do consumo de energia utilizada pela } \\
\text { organização em comparação aos últimos três anos. }\end{array}$ \\
\hline $\begin{array}{l}\text { Desenvolvimento de } \\
\text { tecnologias equilibradas }\end{array}$ & $\begin{array}{l}\text { Analisar as práticas relativas às estratégias voltadas ao } \\
\text { desenvolvimento de tecnologias em equilíbrio com o meio } \\
\text { ambiente. }\end{array}$ \\
\hline $\begin{array}{l}\text { Ciclo de vida de produtos e } \\
\text { serviços }\end{array}$ & $\begin{array}{l}\text { Analisar ciclo de vida de produtos comercializados pela } \\
\text { empresa em relação ao meio ambiente. }\end{array}$ \\
\hline $\begin{array}{l}\text { Quantidade de combustível } \\
\text { fóssil utilizado por ano }\end{array}$ & $\begin{array}{l}\text { Analisar o consumo de combustíveis fósseis em relação ao } \\
\text { nível histórico esperado. }\end{array}$ \\
\hline $\begin{array}{l}\text { Reciclagem e reutilização de } \\
\text { água }\end{array}$ & Analisar a reciclagem e reutilização de água. \\
\hline Acidentes ambientais & $\begin{array}{l}\text { Analisar os acidentes ambientais registrados no âmbito da } \\
\text { organização. }\end{array}$ \\
\hline
\end{tabular}




\begin{tabular}{|l|l|}
\hline Fontes de recursos utilizados & $\begin{array}{l}\text { Analisar a natureza das principais fontes de energia primária } \\
\text { (renováveis e não renováveis). }\end{array}$ \\
\hline Redução de resíduos & $\begin{array}{l}\text { Analisar as práticas associadas à redução de emissão de } \\
\text { resíduos sólidos, líquidos e gasosos gerados pelas } \\
\text { operaçães. }\end{array}$ \\
\hline Produção de resíduos tóxicos & $\begin{array}{l}\text { Analisar as práticas de monitoramento e controle da geração } \\
\text { de resíduos tóxicos. }\end{array}$ \\
\hline ISO 14001 & $\begin{array}{l}\text { Analisar a situação da organização em relação à utilização } \\
\text { das normas ISO 14001. }\end{array}$ \\
\hline Qualidade do solo & $\begin{array}{l}\text { Analisar a geração de danos causados ao solo, bem como as } \\
\text { ações adotadas para a redução de seus impactos. }\end{array}$ \\
\hline $\begin{array}{l}\text { Qualidade de águas de } \\
\text { superfície }\end{array}$ & $\begin{array}{l}\text { Analisar a geração de danos às águas de superfície, bem } \\
\text { como as ações adotadas para a redução de seus impactos. }\end{array}$ \\
\hline
\end{tabular}

Fonte: Callado (2010).

Quanto à dimensão social, Sachs (2008) chama a atenção para a disparidade existente em muitos locais e entre os grupos sociais, sendo o principal objetivo dessa dimensão minimizar essas diferenças existentes. As principais preocupações dessa perspectiva são o bem-estar, as condições humanas e os meios empregados para alcançar essas condições.

Uma sociedade sustentável tem como pressuposto que todos os cidadãos tenham o mínimo necessário para uma vida digna e que ninguém absorva bens, recursos naturais e energéticos que possam ser prejudiciais a outros. Isso significa erradicar a pobreza e definir o padrão de desigualdade aceitável, delimitando limites mínimos e máximos de acesso a bens materiais (NASCIMENTO, 2012).

O envolvimento das organizações com responsabilidade social desencadeia ações que potencializam a confiabilidade dos interessados e envolvidos, pois a 
organização que desenvolve suas atividades de forma ética luta para tornar o ambiente organizacional um lugar agradável para o labor, demonstra respeito pelo meio ambiente e almeja fazer a diferença para uma sociedade melhor (THOMPSON; STRICKLAND III; GAMBLE, 2008).

Rabelo e Silva (2011) destacam que a responsabilidade social compõe a estratégia de longo prazo para sustentabilidade, quando a organização observa e desenvolve ações na tentativa de mudar os efeitos de suas atividades em meio à sociedade. Destacam ainda que as organizações que desenvolveram práticas organizacionais sustentáveis capazes de mudar os valores e os sistemas operacionais estão envolvidas com as concepções de um desenvolvimento sustentável e com responsabilidade social.

Para a dimensão social, Callado (2010) sistematizou um grupo de 12 indicadores. O Quadro 06 apresenta os indicadores e os respectivos parâmetros a serem considerados tanto para tomar decisões estratégicas, quanto na avaliação desta dimensão.

Quadro 06 - Indicadores de sustentabilidade social.

\begin{tabular}{|l|l|}
\hline \multicolumn{1}{|c|}{ Indicador } & \multicolumn{1}{c|}{ Parâmetro de avaliação } \\
\hline Geração de trabalho e renda & $\begin{array}{l}\text { Analisar a importância de ações desenvolvidas pela organização para fins } \\
\text { de desenvolvimento da comunidade local através da geração de trabalho } \\
\text { e renda. }\end{array}$ \\
\hline $\begin{array}{l}\text { Auxílio em educação e } \\
\text { treinamento }\end{array}$ & Analisar os recursos utilizados para capacitação de funcionários. \\
\hline Padrão de segurança de trabalho & $\begin{array}{l}\text { Analisar a utilização de padrões rígidos em questões associadas à } \\
\text { segurança de trabalho no âmbito da organização. }\end{array}$ \\
\hline Ética organizacional & $\begin{array}{l}\text { Analisar a utilização de normas ou códigos de conduta profissional no } \\
\text { âmbito da organização. }\end{array}$ \\
\hline Interação social & Analisar as ações e iniciativas da organização voltadas para sua \\
\hline
\end{tabular}




\begin{tabular}{|c|c|}
\hline & integração com a sociedade. \\
\hline $\begin{array}{l}\text { Empregabilidade e } \\
\text { gerenciamento de fim de carreira }\end{array}$ & $\begin{array}{l}\text { Analisar as ações da organização voltadas para a promoção da } \\
\text { empregabilidade, bem como para o gerenciamento no fim de carreira de } \\
\text { seus funcionários. }\end{array}$ \\
\hline $\begin{array}{l}\text { Políticas de distribuição de lucros } \\
\text { e resultados }\end{array}$ & $\begin{array}{l}\text { Analisar as práticas de distribuição de lucros e resultados entre os } \\
\text { funcionários. }\end{array}$ \\
\hline Conduta de padrão internacional & $\begin{array}{l}\text { Analisar a adoção de condutas sociais de acordo com padrões } \\
\text { estabelecidos internacionalmente por intermédio de organismos } \\
\text { internacionais, a exemplo da ONU, da FAO e da OECD. }\end{array}$ \\
\hline Capacitação e desenvolvimento & Analisar as políticas de capacitação e desenvolvimento de funcionários. \\
\hline Acidentes fatais & Analisar a ocorrência de acidentes fatais associados ao trabalho. \\
\hline Contratos legais & $\begin{array}{l}\text { Analisar as características dos contratos que regem a relação entre } \\
\text { proprietários e funcionários. }\end{array}$ \\
\hline Stress de trabalho & $\begin{array}{l}\text { Analisar a maneira pela qual a empresa lida com o stress no ambiente de } \\
\text { trabalho. }\end{array}$ \\
\hline
\end{tabular}

Fonte: Callado (2010).

Os indicadores de sustentabilidade sugeridos por Callado (2010) compuseram os construtos inerentes às dimensões econômica, ambiental e social a serem analisados por este estudo.

\subsection{Cooperativas agropecuárias no contexto brasileiro}

De acordo com a OCB (2016), as cooperativas agropecuárias brasileiras são organizações de produtores rurais ou agropastoris e de pesca, nas quais os meios de produção pertencem ao cooperado. Caracterizam-se principalmente pelos serviços prestados aos associados, como recebimento ou comercialização da produção conjunta, armazenamento e industrialização, além da assistência técnica, educacional e social. 
O cooperativismo agropecuário é a atividade associativista mais conhecida pela sociedade brasileira, estando presente em quase todo território nacional (YOUNG, 2010). Esse ramo possui 1.597 cooperativas, com 1 milhão de associados, promovendo 164.320 empregos diretos (OCB, 2015). Essa importância advém da participação, de forma significativa, no comércio internacional, influenciando o comportamento da balança comercial brasileira e suprindo as demandas do mercado interno. Diante desta conjuntura, pode-se inferir que é o ramo economicamente mais influente do cooperativismo brasileiro.

Esse ramo cooperativista é responsável por boa parte da produção alimentícia consumida pelos brasileiros. Segundo dados do Instituto Brasileiro de Geografia e Estatística (IBGE), referentes ao ano de 2016, o modelo cooperativista representava aproximadamente $48 \%$ do total da produção de alimentos do país, com importante papel na produção e distribuição de produtos, como leite, café, trigo, soja, arroz, feijão, carnes, legumes, frutas e demais produtos alimentícios.

Buscando explicar o porquê da predominância do ramo agropecuário no cooperativismo brasileiro, Bialoskorski Neto (2010) destaca que a atividade agrícola, como um setor econômico primário, interage, tanto a montante como a jusante na cadeia produtiva, com oligopólios. No entanto, a atividade agropecuária tende a ser competitiva por ser tomadora de preços quando da aquisição de insumos e comercialização dos resultados da produção. Assim, a formação de estruturas econômicas intermediárias, como são as organizações cooperativas, potencializam a redução de riscos e agregação de valor para os produtores associados que, se negociassem de forma individual, não obteriam resultados satisfatórios na negociação com um mercado oligopolista.

De acordo com a OCB (2015), o cooperativismo agropecuário é responsável pela inclusão dos produtores no mercado. Segundo dados do Ministério do 
Desenvolvimento Agrário (MDA), 76\% das famílias cooperadas com Declaração de Aptidão da Agricultura Familiar (DAPF) no país integram o Sistema OCB. Esta conjuntura evidencia a importância deste ramo para que os produtores possam acessar tecnologias e insumos, bem como para ganhar economia de escala nos processos de compra e venda e acesso ao mercado.

\section{PROCEDIMENTOS METODOLÓGICOS}

Nesta seção, são apresentados o desenho da pesquisa, composto pela população e amostra, a abordagem e características da pesquisa, o delineamento do estudo, considerando a perspectiva temporal, o nível e unidade de análise, bem como os procedimentos e técnicas utilizados para a coleta e análise dos dados.

Para a presente pesquisa, o universo ou população pesquisada compreendeu a totalidade de organizações cooperativas agropecuárias em atividade na Região Sul do Brasil (estados do Paraná, Santa Catariana e Rio Grande do Sul). De acordo com levantamento junto a instituições que representam as cooperativas, atualmente 246 organizações cooperativas agropecuárias estão desenvolvendo suas operações.

As 246 cooperativas agroindustriais atuantes na Região Sul do Brasil foram convidadas a participar do estudo, 94 destas responderam o instrumento de coleta de dados. Primeiramente, buscou-se avaliar a existência de valores perdidos e de valores extremos (outliers), com auxílio do pacote estatístico SPSS ${ }^{\circledR}$ versão 22 (Statistical Package for the Social Sciences). Após esta avaliação, a amostra confirmou-se em 93 casos, representando, assim, 37,80\% da população pesquisada.

Quanto à localização (Estado) da sede das cooperativas participantes do estudo, os dados dispostos na Tabela 01 apresentam de forma comparativa a distribuição da população bem como da amostra estudada. A distribuição entre 
população e amostra mostra-se equilibrada nos aspectos referentes à localização das cooperativas agropecuárias.

Tabela 01 - Comparativo da localização entre população e amostra

\begin{tabular}{c|c|c|c|c}
\hline Localização (sede) & \multicolumn{2}{|c|}{ População } & \multicolumn{2}{c}{ Amostra } \\
\hline & Frequência & $\%$ & Frequência & $\%$ \\
\hline Paraná & 69 & 28,0 & 31 & 33,3 \\
\hline Santa Catarina & 52 & 21,1 & 18 & 19,4 \\
\hline Rio Grande do Sul & 125 & 50,8 & 44 & 47,3 \\
\hline Total & 246 & 100,0 & 93 & 100,0 \\
\hline
\end{tabular}

Fonte: Dados da pesquisa (2017).

A representatividade da amostra foi avaliada com a aplicação do teste ChiSquare, ou adequação ao ajustamento (goodness of fit), também denominado de teste de aderência. Este teste compara a proporção de casos de uma amostra com valores hipotéticos ou aqueles obtidos anteriormente de uma população. (PALLANT, 2010). A Tabela 02 apresenta os resultados para o teste de aderência entre população e amostra, o qual apresentou significância estatística $(p>0,05)$ entre a população e a amostra estudada.

Tabela 02 - Teste de aderência (chi-square) entre população e amostra

\begin{tabular}{c|c|c|c}
\hline Localização (sede) & $\mathrm{N}^{\circ}$ Observado & $\mathrm{N}^{\circ}$ Esperado & Residual \\
\hline Paraná & 31 & 26,1 & 4,9 \\
\hline Santa Catarina & 18 & 19,7 & $-1,7$ \\
\hline Rio Grande do Sul & 44 & 47,2 & $-3,2$ \\
\hline Total & 93 & 93 & \\
\hline
\end{tabular}




\begin{tabular}{|c|c|c|c|}
\hline Localização (sede) & $\mathrm{N}^{\circ}$ Observado & $N^{\circ}$ Esperado & Residual \\
\hline Paraná & 31 & 26,1 & 4,9 \\
\hline Santa Catarina & 18 & 19,7 & $-1,7$ \\
\hline Rio Grande do Sul & 44 & 47,2 & $-3,2$ \\
\hline \multicolumn{3}{|c|}{ Chi-Square test } & $1,290 a$ \\
\hline \multicolumn{3}{|c|}{ Significância estatística - Teste Chi-Square $(p>0,05)$} & 0,525 \\
\hline
\end{tabular}

Fonte: Dados da pesquisa (2017).

Quanto à abordagem, esta pesquisa buscou respostas ao problema proposto ancorada em uma abordagem quantitativa que, segundo Roesch (2006), não busca representatividade subjetiva, mas encontrar associações e explicações preditivas. Esta abordagem tem como enfoque delineamentos analíticos ou relacionais, planejados para explorar as associações entre um grupo de variáveis. A abordagem quantitativa assume uma característica descritiva nesta pesquisa, a qual, de acordo com Hair Jr. et al. (2009), presume-se em uma análise descritiva ex post facto.

Quanto aos objetivos propostos, a pesquisa teve um caráter exploratório e descritivo, pois a intenção do estudo é proporcionar ao pesquisador maior conhecimento sobre um determinado fenômeno, no qual o pesquisador parte de pressupostos e hipóteses e aprofunda seus estudos nos limites de uma realidade específica, buscando antecedentes e conhecimentos para torná-lo explícito (TRIVINOS, 1987).

Quanto à perspectiva temporal, esta pesquisa apresenta-se em um corte transversal, operacionalizada por meio de um levantamento, este denominado por Malhotra (2012) como survey cross-sectional. De acordo com Hair Jr. et al. (2009), este procedimento de coleta de dados primários permite levantar crenças, opiniões, atitudes e informações gerais sobre indivíduos, bem como características de uma organização. A unidade de análise, a ser representada na operacionalização, foram às 
organizações cooperativas agropecuárias, as quais foram convidadas a participar respondendo ao questionário de pesquisa.

Para coleta de dados foi desenvolvido um questionário estruturado com base nos pressupostos teóricos elencados para fundamentar este estudo e nas definições conceituais e operacionais. Para validação do instrumento de coleta de dados, foram realizadas alterações observando sugestão de especialistas (pesquisadores nas áreas de sustentabilidade, inovação e agronegócio). Após a avaliação dos especialistas, o instrumento (no formato eletrônico) foi aplicado na condição de teste junto a duas cooperativas, observou-se o tempo para responder as questões, a linguagem utilizada, e ainda, se as respostas apresentaram proximidade em resultados.

As organizações cooperativas filiadas às organizações OCEPAR, OCESC e OCERGS foram convidadas a participar da pesquisa por meio de um primeiro contato via telefone, com o intuito de esclarecer o propósito da pesquisa e de obter um maior número de respostas e confirmação de dados dos possíveis gestores respondentes. $\mathrm{O}$ instrumento de pesquisa foi enviado via correio eletrônico (e-mail) diretamente ao respondente com as devidas orientações para preenchimento. O gestor teve duas opções para responder a pesquisa, sendo uma preenchendo em formulário WordMicrosoft ${ }^{\circledR}$, ou em formulário online no sistema GoogleDocs, disponibilizado de forma gratuita pelo Google ${ }^{\circledR}$. A coleta dos dados ocorreu nos meses de agosto e setembro de 2017.

Os dados coletados pelo instrumento de pesquisa foram tabulados e analisados com o auxílio dos softwares Microsoft Office Excel ${ }^{\circledR}$ e Statistical Package for the Social Sciences - SPSS ${ }^{\circledR}$ (versão 22), por meio da adoção de modelos de análise univariados, bivariados e multivariados. Para a aplicação das técnicas, foram considerados os pressupostos elencados na literatura (FIELD, 2009; DANCEY; REIDY, 
2006; HAIR JR. et al., 2009; FAVERO et al., 2009; CORRAR; PAULO; DIAS FILHO, 2007; PALLANT, 2010).

\section{APRESENTAÇÃO E ANÁLISE DOS RESULTADOS}

\subsection{Caracterização da amostra participante do estudo}

Enquanto síntese a partir dos dados levantados e analisados, a amostra de cooperativas agropecuárias estudadas tem como características ser de médio e grande porte, com tempo médio de existência de 39 anos. Quanto ao perfil considerando a origem dos produtos, as cooperativas pesquisadas são essencialmente agrícolas, e a fonte destes produtos, em sua maioria, dos cooperados. As cooperativas têm a maior parte de seu faturamento resultante das operações em mercado nacional com agregação de valor aos produtos e processos, e apenas uma minoria das cooperativas tem suas operações com commodities. Quanto ao perfil dos gestores, estes estão no cargo em média há 9 anos e estão vinculados à cooperativa em média há 17 anos. Estes dados sugerem que os gestores respondentes da pesquisa possuem conhecimentos suficientes sobre as questões abordadas pelo estudo.

4.2 Caracterização das cooperativas - uma proposta de taxonomia

Com o objetivo de caracterizar as cooperativas agropecuárias em função do foco dado à inovação tanto em produto quanto em processos, fez-se uso da análise de cluster, ou análise de agrupamentos. De acordo com Corrar, Paulo e Dias Filho (2007), é uma técnica de análise multivariada caracterizada como descritiva, ateorética e não inferencial, cujo propósito é desenvolver descrições taxonômicas.

A aplicação desta técnica é precipuamente exploratória para a formação de uma taxonomia, uma classificação de objetos com base empírica (FÁVERO et al., 
2009). Busca agrupar casos de uma amostra em subgrupos, os quais terão similaridade enquanto são diferentes entre si, assim, busca-se identificar subgrupos que apresentem diferenças de comportamento, possibilitando a definição adequada para cada grupo, em função das suas características específicas (HAIR et al., 2005).

Para propor a taxonomia, o método não hierárquico de aglomeração ou de realocação denominado $k$ médias ( $K$-means clustering) foi o selecionado, definindo a priori que o número de agrupamentos deveria ser igual a quatro. Esta quantidade de grupos foi escolhida pelos pesquisadores com objetivo de classificar as cooperativas de acordo com o foco dado à inovação. O Quadro 06 apresenta a classificação proposta.

Quadro 06 - Taxonomia de inovação para cooperativas agropecuárias

\begin{tabular}{|c|c|}
\hline Taxonomia & Características \\
\hline $\begin{array}{l}\text { Cooperativas com foco } \\
\text { inovador em produtos e } \\
\text { processos }\end{array}$ & $\begin{array}{l}\text { Apresentam altos escores nos construtos Desempenho Inovador em } \\
\text { Produtos (V1-DI_PROD a V11-DI_PROD) e em Desempenho Inovador } \\
\text { em Processos (V1-DI_PROC a V9-DI_PROC). }\end{array}$ \\
\hline $\begin{array}{l}\text { Cooperativas com foco } \\
\text { inovador em Produtos }\end{array}$ & $\begin{array}{l}\text { Apresentam altos escores nos construtos Desempenho Inovador em } \\
\text { Produtos (V1-DI_PROD a V11-DI_PROD) e baixos scores em } \\
\text { Desempenho Inovador em Processos (V1-DI_PROC a V9-DI_PROC). }\end{array}$ \\
\hline $\begin{array}{l}\text { Cooperativas com foco } \\
\text { inovador em Processos }\end{array}$ & $\begin{array}{l}\text { Apresentam baixos escores nos construtos Desempenho Inovador } \\
\text { em Produtos (V1-DI_PROD a V11-DI_PROD) e altos scores em } \\
\text { Desempenho Inovador em Processos (V1-DI_PROC a V9-DI_PROC). }\end{array}$ \\
\hline $\begin{array}{l}\text { Cooperativas sem foco para } \\
\text { inovação }\end{array}$ & $\begin{array}{l}\text { Apresentam baixos escores nos construtos Desempenho Inovador } \\
\text { em Produtos (V1-DI_PROD a V11-DI_PROD) e em Desempenho } \\
\text { Inovador em Processos (V1-DI_PROC a V9-DI_PROC). }\end{array}$ \\
\hline
\end{tabular}

Fonte: Dados da Pesquisa (2017).

De acordo com Fávero et al. (2009), no conjunto de técnicas para definição dos agrupamentos, a análise por meio da ANOVA (Analysis of Variance) indica se as 
variáveis utilizadas permitem distinguir de forma satisfatória os agrupamentos, onde se espera uma variabilidade elevada entre os grupos e uma variabilidade interna mínima nos grupos. Os resultados demonstraram valores de Sig. F significativos ao nível de $5 \%(p<0,05)$ para todas as variáveis que compuseram os clusters propostos para as cooperativas agropecuárias da amostra analisada. O centro (média) dos clusters é apresentado na Tabela 03.

Tabela 03 - Centro médio dos clusters

\begin{tabular}{c|c|c|c|c}
\hline \multirow{2}{*}{ Desempenho Inovador } & \multicolumn{4}{|c}{ Clusters } \\
\cline { 2 - 5 } & 1 & 2 & 3 & 4 \\
\hline Inovação em Produtos & 3,357 & 2,170 & 1,688 & 2,942 \\
\hline Inovação em Processos & 3,881 & 3,065 & 1,960 & 2,917 \\
\hline
\end{tabular}

Fonte: Dados da Pesquisa (2017).

Após a aplicação das técnicas e o resultado da análise de cluster, tem-se a taxonomia proposta da seguinte forma: Cluster 1 - 26 Cooperativas com foco inovador em produtos e processos; Cluster 2 - 24 Cooperativas com foco inovador em processos; Cluster 3 - 14 Cooperativas sem foco em inovação; e Cluster 4 - 29 Cooperativas com foco inovador em produtos. Observa-se que o Cluster 4, caracterizado pelo foco inovador em produtos, apresentou médias próximas entre o foco inovador em produtos $(2,947)$ e para processos $(2,917)$. A Figura 01 apresenta na forma de matriz a composição da taxonomia proposta. 
Figura 01 - Clusters cooperativas agropecuárias

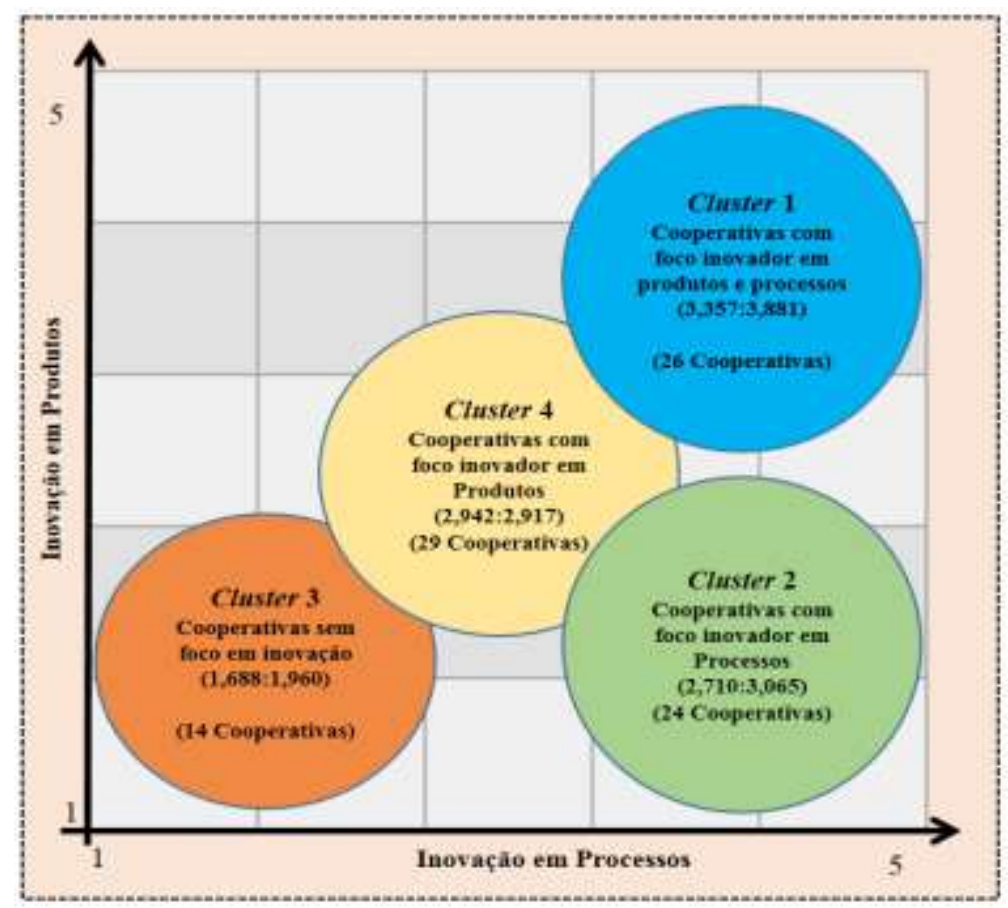

Fonte: Dados da Pesquisa (2017).

A taxonomia proposta a partir dos clusters formados possibilitou aprofundar as análises junto aos construtos que avaliam o processo de formulação das estratégias das cooperativas e as dimensões da sustentabilidade. Para avaliar se havia diferenças entre os construtos e os clusters, fez-se uso do teste One-Way ANOVA. Este teste permite verificar o efeito de uma variável independente de natureza qualitativa (fator) em uma variável dependente de natureza quantitativa e examina se existe diferença entre os diversos grupos (sempre mais que dois grupos), comparando a variância entre os diferentes grupos com a variabilidade dentro de cada grupo (PALLANT, 2010).

Buscou-se então verificar se as cooperativas agropecuárias pesquisadas (clusters) apresentavam diferenças (a partir das médias) em relação às dimensões da sustentabilidade (econômica, ambiental e social). Os resultados demonstraram que há diferença entre os clusters com as três dimensões avaliadas. Quando avaliada a "Dimensão Econômica", as cooperativas com foco inovador em produtos e processos 
(Cluster 1) apresentaram diferenças em relação às cooperativas sem foco em inovação

(Cluster 3) e com as cooperativas com foco inovador em processos (Cluster 2). Este mesmo resultado se apresentou quando avaliado se havia diferenças entre os clusters e a "Dimensão Social". A Tabela 04 apresenta a síntese dos resultados a partir do teste One-Way ANOVA.

Tabela 04 - One-Way ANOVA para clusters e dimensões da sustentabilidade

\begin{tabular}{l|c|c|c|c}
\hline Dimensão & $\begin{array}{c}\text { Sig. Teste } \\
\text { Levene }\end{array}$ & $F$ & $\begin{array}{c}\mathrm{p} \text { - valor } \\
(\text { Sig.) }\end{array}$ & Resultado \\
\hline Econômica & 0,736 & 12,171 & 0,000 & Cluster 1 $\neq$ Cluster 3 \\
\hline Ambiental & 0,754 & 6,025 & 0,001 & Cluster 1 $\neq$ Cluster 2 \\
\hline Social & 0,624 & 19,476 & 0,000 & Cluster 3 \\
& & & & Cluster 1 $\neq$ Cluster 2 \\
\hline
\end{tabular}

Fonte: Dados da Pesquisa (2017).

Quando avaliada a "Dimensão Ambiental", as cooperativas com foco inovador em produtos e processos (Cluster 1) se mostraram diferentes das cooperativas sem foco inovador (Cluster 3). Diante dos resultados apresentados, a partir da comparação entre as dimensões da sustentabilidade e as cooperativas agropecuárias estudadas, sugere-se que as cooperativas com foco inovador em produtos e processos (Cluster 1) têm diferenças significativas com as cooperativas sem foco inovador (Cluster 3), e estas diferenças podem estar associadas à concepção das cooperativas em incorporar a sustentabilidade de forma que possa contribuir para o desempenho inovador da organização. 


\section{CONSIDERAÇÕES FINAIS}

Para caracterizar as cooperativas agropecuárias em função da postura inovadora, considerando o foco inovador para produtos e processos, ou ambos, fezse uso da técnica de agrupamentos, propondo uma taxonomia a partir das cooperativas participantes da pesquisa. A taxonomia se constituiu em quatro clusters, sendo: Cluster 1 - 26 cooperativas com foco inovador em produtos e processos; Cluster 2 - 24 cooperativas com foco inovador em processos; Cluster 3 - 14 cooperativas sem foco em inovação; e Cluster 4 - 29 cooperativas com foco inovador em produtos. Embora o Cluster 4 tenha apresentado foco inovador em produtos, verifica-se, a partir das médias, que a inovação em processos também está presente. Esta característica parece ser inerente a atividades com operações vinculadas a commodities, nas quais a inovação em processos é predominante.

Quando comparados com as dimensões da sustentabilidade, os resultados demonstraram que há diferença entre os clusters e as três dimensões avaliadas, com destaque para as cooperativas com foco inovador em produtos e processos (Cluster 1), pois estas apresentaram diferenças em relação aos demais clusters. Pode-se sugerir que estas diferenças estão associadas à concepção das cooperativas em incorporar a sustentabilidade, de forma que possa contribuir para o desempenho inovador destas organizações.

Em síntese, os resultados demonstram que há diferença no foco dado à inovação em produtos e processos por estas organizações, e nota-se ainda que as cooperativas agropecuárias que vêm considerando os aspectos inerentes à sustentabilidade podem estar potencializando seu desempenho inovador tanto em produtos quanto em processos. 
O desenvolvimento deste estudo assentou-se em opções metodológicas alinhadas ao problema de pesquisa e aos objetivos definidos para o estudo, no entanto, é sabido que as tentativas de captar nuances da realidade apresentam limitações, as quais podem estar associadas às escolhas do pesquisador, ou ainda serem decorrentes das técnicas e métodos aplicados na operacionalização da pesquisa.

Outra limitação está associada aos dados obtidos a partir de uma amostragem não probabilística, e sim por conveniência e aceitação das cooperativas agropecuárias, de forma que os resultados não permitem extrapolar em generalizações, devendo ser considerados no âmbito da amostra investigada, ou, se estendidos, estes não devem ultrapassar o contexto das organizações cooperativas do ramo agropecuário atuantes na Região Sul do Brasil.

\section{REFERÊNCIAS}

BIALOSKORSKI NETO, S. Aspectos econômicos das cooperativas. Belo Horizonte: Mandamentos, 2010.

CALLADO, A. L. C. Modelo de mensuração de sustentabilidade empresarial: uma aplicação em vinícolas localizadas na serra gaúcha. 215 f. Tese. Doutorado em Agronegócio. Centro de Estudos e Pesquisas em Agronegócios. Universidade Federal do Rio Grande do Sul, Porto Alegre, 2010.

CMMAD - Comissão Mundial sobre Meio Ambiente e Desenvolvimento. Nosso futuro comum. 2. ed. Rio de Janeiro: Editora da FGV, 1991.

CORRAR, L. J.; PAULO, E.; DIAS FILHO, J. M. Análise multivariada: para os cursos de administração, ciências contáveis e economia. São Paulo: Atlas, 2007. 
DALÉ, L. B. C.; ROLDAN, L. B.; HANSEN, P. B. Analysis of Sustainability Incorporation by Industrial Supply Chain in Rio Grande do Sul State (Brazil) Journal of Operations and Supply Chain Management, 4 (1), p. 25 - 36, 2011.

DAROIT, D.; NASCIMENTO, L. F. Dimensões da inovação sob o paradigma do desenvolvimento sustentável. In: $28^{\circ}$ Encontro Nacional da ANPAD, Curitiba/PR. Anais..., 2004.

DIEGUES, A. C. A ecologia política das grandes ONGS transnacionais conservacionistas. São Paulo: HUCITEC - NUPAUB, 2008.

ELKINGTON, J. Sustentabilidade, canibais de garfo e faca. São Paulo: M. Books, 2011. 488 .

FÁVERO, L. P; BELFIORE, P.; SILVA, F. L.; CHAN, B. L. Análise de dados: modelagem multivariada para tomada de decisão. Rio de Janeiro: Elsevier, 2009.

FIELD, A. Descobrindo a estatística usando o SPSS. 2. ed. Porto Alegre: Bookman, 2009. GUNDAY, G.; ULUSOY, G,; KILIC, K.; ALPKAN, L. Effects of innovation types on firm performance. International Journal Production Economics, v. 133, p. 662-676, 2011.

HAIR, J.; BLACK, W. C.; BABIN, B. B.; ANDERSON, R. E.; TATHAM, R. L.; Análise multivariada de dados. 6. ed. Porto Alegre: Bookman, 2009.

JACOBS, F. R.; CHASE, R. B. Administração das operações e da cadeia de suprimentos. 13. ed. Porto Alegre: AMGH, 2012.

LUNDVALL, B. (Ed). Nacional systems of innovation: toward a theory of innovation and interactive learning. Ed. Anthem Press. London, UK, 2010. Cap. 1 e 2, p. 1-46. 
MADUREIRA, L.; GAMITO, T. M.; FERREIRA, D.; PORTELA, J. Inovação em Portugal Rural: detetar, medir e valorizar. Cascais: Editora Pincipia, 2013.

MAKKONEN, T.; VAN DER HAVE, R. P. Benchmarking regional innovative performance: composite measures and direct innovation counts. Scientometrics, Budapest, Hungary, 2012.

MALHOTRA, N. K. Pesquisa de marketing: uma orientação aplicada. 6. ed. Porto Alegre: Bookman, 2012.

MAPA - MINISTÉRIO DA AGRICULTURA, PECUÁRIA E ABASTECIMENTO. CurSO de propriedade intelectual e inovação no agronegócio. Ministério da agricultura, pecuária e abastecimento. Luiz Otávio Pimentel (Org.). Brasília: MAPA, 2009.

NASCIMENTO, E. P. Trajetória da sustentabilidade: do ambiental ao social, do social ao econômico. Estudos Avançados, v. 26, n. 74, p. 51-64, 2012.

OCB - Organização das Cooperativas Brasileiras. Agenda institucional do cooperativismo. Brasília: Sistema OCB, 2015. Disponível em: www.brasilcooperativo.coop.br. Acesso em: 18 Ago., 2016.

OCB - Organização das Cooperativas Brasileiras. Cooperativismo em toda parte. Disponível em: http://www.ocb.org.br/site/ramos/index.asp. Acesso em: 17 Ago., 2016.

OECD. Manual de Oslo: diretrizes para coleta e interpretação de dados sobre inovação. 3. ed. FINEP, Brasil, 2007.

PALLANT, J. SPSS Survival Manual. 5th Edition. Berkshire: McGraw-Hill, 2010. 
PORTO, G. S. Gestão da inovação e empreendedorismo. Rio de Janeiro: Elsevier, 2013.

RABELO, N. S.; SILVA, C. E. Modelos de Indicadores de Responsabilidade Socioambiental Corporativa. Revista Brasileira de Administração Científica, v. 2, n. 1, p.2-10, jun. 2011.

REICHERT, F. M.; CAMBOIM, G. F.; ZAWISLAK, P. A. Capacidades e trajetórias de inovação de empresas brasileiras. Revista de Administração Mackenzie, v. 16, n. 5, Set./Out., p. 161-194, 2015.

ROESCH, S. M. A. Projetos de estágio e de pesquisa em administração: guia para estágios, trabalhos de conclusão, dissertações e estudos de caso. 3. ed. São Paulo: Atlas, 2006.

SACHS, I. Caminhos para o desenvolvimento sustentável. 3. ed. Rio de Janeiro: Garamond, 2008.

SANTOS, J. A. M.; TAVARES, M. C.; VASCONCELOS, M. C. R. L.; AFONSO, T. O processo de inovação tecnológica na Embrapa e na Embrapa Agrobiologia: desafios e perspectivas. Perspectivas em Ciência da Informação, v.17, n.4, p.175-194, out./dez. 2012.

SCHALTEGGER, S.; LUDEKE-FREUND, F.; HANSEN, E. G. Business cases for sustainability and the role of business model innovation: developing a conceptual framework. Centre for Sustainability Management (CSM), Leuphana Universitat Lüneburg Scharnhorststr. 2011, p. 1-32.

SCHVARZ SOBRINHO, R. Proposta de estrutura para análise da natureza das inovações em organizações: uma aplicação em cooperativas agropecuárias paranaenses. 193 f. Tese (doutorado) Programa de Pós-Graduação em Agronegócios, 
Escola de Administração, Universidade Federal do Rio Grande do Sul, Porto Alegre, 2009.

SOUZA, A. S.; SILVA FILHO, J. L.; ABREU, M. C. S. Estratégias para a sustentabilidade: um estudo multicasos sobre empresas em operação no estado do Ceará. Revista Economia, v. 45, n. 3, p. 135-157, jul-set., 2014.

SPIELMAN, D. J.; KELEMEWORK, D. Measuring agricultural innovation system properties and performance: illustrations from Ethiopia and Vietnam. International Service for National Agricultural Research Division, Washington, 2009.

THOMPSON, A. A.; STRICKLAND III, A. J.; GAMBLE, J. E. Administração estratégica. 15. ed. São Paulo: McGraw Hill, 2008.

TIDD, J.; BESSANT, J. Gestão da inovação. 5. ed. Porto Alegre: Bookman, 2015.

VEIGA, J. E. Desenvolvimento sustentável: o desafio do século XXI. São Paulo: Garamond, 2006.

VIEIRA, M. M. F. Por uma boa pesquisa (qualitativa) em administração. In: VIEIRA. M. M. F.; ZOUAIN, D. M (Org.). Pesquisa qualitativa em administração. 2. ed. Rio de Janeiro: Editora FGV, p. 13-28, 2006.

VIEIRA FILHO, J. E. R.; VIEIRA, A. C. P. Panorama das inovações na pesquisa agrícola no Brasil: o sistema de propriedade intelectual. Instituto de Pesquisa Econômica Aplicada (Ipea), n. 24, p. 51-60, 2014.

WU, Z.; PAGELL, M. Balancing priorities: decision-making in sustainable supply chain management. Journal of Operations Management. 29, p. 577-590, 2011. 
37 | ROCHA, A. C.; STEINER NETO, P. J.

YOUNG, L. H. B. Sociedades cooperativas: resumo prático. 8. ed. Curitiba: Juruá, 2008. 
